\title{
The Exploitation of Indigenous Knowledge or the Indigenous Exploitation of Knowledge: Whose Use of What for What?
}

Martin Bell

"Producing technology . . means producing instruments of control and influence over other individuals, firms and nations. The capacity of technology to transform the nature, orientation and purpose of development is such that the question of who controls technology is central to who controls development".

'What Now'; The 1975 Dag Hammarskjöld Report.

This paper discusses three questions about the uses of indigenous technical knowledge in development:

-What are we talking about when we use the term 'indigenous technical knowledge'?

-Why should indigenous technical knowledge be a subject of policy concern?

-What 'uses' might be made of indigenous technical knowledge?

Before dealing with these questions, it may be useful to point out an important limitation of the paper. It is concerned with technical knowledge which is indigenous to socio-economically disadvantaged groups in rural areas within underdeveloped countries. ${ }^{1}$ However it does not focus on that issue in isolation. To answer the questions posed above, it is necessary to examine not just 'indigenous technical knowledge', but the relationship between that knowledge and other technical knowledge.

The technological poverty of rural groups is just one dimension of more general rural poverty, and this in turn must be seen in the context of relationships between the rural poor and other social groups - between those which have wealth, welfare and power and those which do not. So also with the technological dimension of rural poverty. One must examine not merely the

1 This concept of 'indigenous technical knowledge' is therefore much narrower than that for which the term is used in the extensive literature which focuses on technology and development at the national level. technology of the rural poor, but the technologycentred relationships between those who have technology, together with the capabilities to create and use it, and those who do not.

However, the nature of technology-centred interactions between disadvantaged rural groups and others results not merely from inequality in the resources for creating and using technical knowledge. This is important, but the technologycentred interactions are set within, and their characteristics are affected by, a much wider structure of social, economic and power relationships. To extract the technology-centred interactions out of this fabric can be misleading. This is certainly so if analytical simplification is carried through to the arena of policy and action.

This, then, is a major limitation of the paper. It focuses almost exclusively on issues about technical knowledge, and may give the impression that technology and technology-centred relationships can be used and manipulated independently of the social, political and economic structures within which they are set. This is not the intention. The paper only attempts to take a number of analytical steps towards policy and action.

\section{Indigenous technical knowledge}

In defining indigenous technical knowledge (ITK), it is probably not useful to see it as different in quality from other kinds of technical knowledge. Distinctions between 'old' and 'new', or 'traditional' and 'modern' knowledge are not likely to help. Knowledge indigenous to the social groups with which we are concerned of ten spans a range of vintages, as illustrated by Swift's comments (infra) on the use of landrover parts by Twareg smiths.

Previous papers in this Bulletin imply that a useful distinction can be made between ITK which is 'non-scientific' and other kinds of technical knowledge which are 'scientific'. This type of distinction also seems likely to be fruitless. It is not at all clear what these terms mean, nor that they can actually be used to distinguish ITK from other kinds of technical knowledge. 
For example, 'non-scientific technical knowledge' might mean technology which did not draw upon and incorporate basic knowledge which had originally been created as science. A great deal of this type of technical knowledge exists, but it is certainly not peculiar to disadvantaged groups in the rural Third World. For example, an enormous amount of the technical knowledge which lies behind the production systems of the advanced, industrial economies was never science. It was always technology. In this sense of the term, it also is 'non-scientific technical knowledge'.

Alternatively, the term 'non-scientific' may be used to describe technical knowledge which was created by processes not involving the use of scientific methods such as systematic observation, quantification, cumulative acquisition, experimentation, and hypothesis testing. Again, a great deal of this kind of knowledge exists, but it is probably not appropriate to define ITK in these terms. ITK is probably often created by processes involving these features of the scientific method-albeit in varying degrees, and with varying formalisation of the procedures.

These kinds of difficulty in formulating clear qualitative distinctions between ITK and other forms of technical knowledge suggest that it is probably more useful not to attempt any such $a$ priori classification, but to define ITK more simply-largely in terms of socio-economic and spatial location. We are concerned with technical knowledge which is rooted and embedded in (indigenous to) specified social groups. These social groups are in this paper defined as rurallylocated and socio-economically underprivileged groups within third world societies. The phrase 'rooted and embedded in' requires explanation. Implicit in some parts of the other papers in this Bulletin is the idea that 'indigenous to' is equivalent to 'created by'. This is unhelpfully restrictive. The stock of technical knowledge which is indigenous to any social group is likely to be a mixture of knowledge created indigenously and knowledge acquired from outside and absorbed and integrated within the group. Technical knowledge which has been indigenously created is only part of our concern.

This does not mean that all technical knowledge with which a social group comes into contact constitutes indigenous technical knowledge. While it may often be hard to draw the distinction, there is much technical knowledge which rural groups encounter which cannot be described as indigenous because it is in no sense rooted in, absorbed into, or integrated within such groups. ${ }^{2}$ To be indigenous, technical knowledge must be not merely present within the given socio-economic and spatial boundaries, but also an active component of the culture of the social group concerned, being stored, communicated, and used by its members to serve some purpose in relation to productive activity within the society.

These comments so far imply that the object of our interest is a particular stock of knowledge. However, a stock-centred perspective would imply, for the purposes of development, little more than a one-off effort to exploit what rural groups know-a kind of functional, but ultimately sterile, antiquarianism. Given the finite limits to the existing stock, the potential uses are also finite. After the one-off exploitation of the existing accumulation of technology-capital had been achieved, one would presumably revert to dependence on exogenous technical knowledge. To avoid this exploitative approach to 'using' ITK, we must start out with a concern which goes beyond using a given stock and encompasses the ongoing accumulation of ITK. This paper therefore defines ITK as including not merely the existing stock of such knowledge, but also the indigenous capabilities to add to that stock and to use it. In effect we are concerned with indigenous technological systems-both as they are, and in terms of their potentials for desirable change.

Figure I illustrates the main components of such a system. It also illustrates how such a system may be used to effect technical change within the process of development. Broadly, the indigenous technology system may be used in two ways. It may be used directly to effect technical change -via linkage A. It may also be used indirectly through interaction with exogenous technology systems - via linkages $\mathrm{C}$ and $\mathrm{B}$.

\section{Why be concerned about indigenous technical knowledge?}

This paper argues that a major concern of policy should be to make far greater use of ITK in effecting rural technical change than is currently

\footnotetext{
2 The un-serviced tractor and the un-used latrine constitute examples of the symptoms of encounters with technical knowledge which does not become rooted in the local culture. Much of the technical knowledge encountered in rural classrooms is probably similar. If it serves any functions other than that of examination-passing, they are functions outside the rut (temporary) injection of something alien which does not become absorbed into the active knowledge-stock of the community.
} 
Figure 1. The Main Components of the System concerned with Indigenous Technical Knowledge

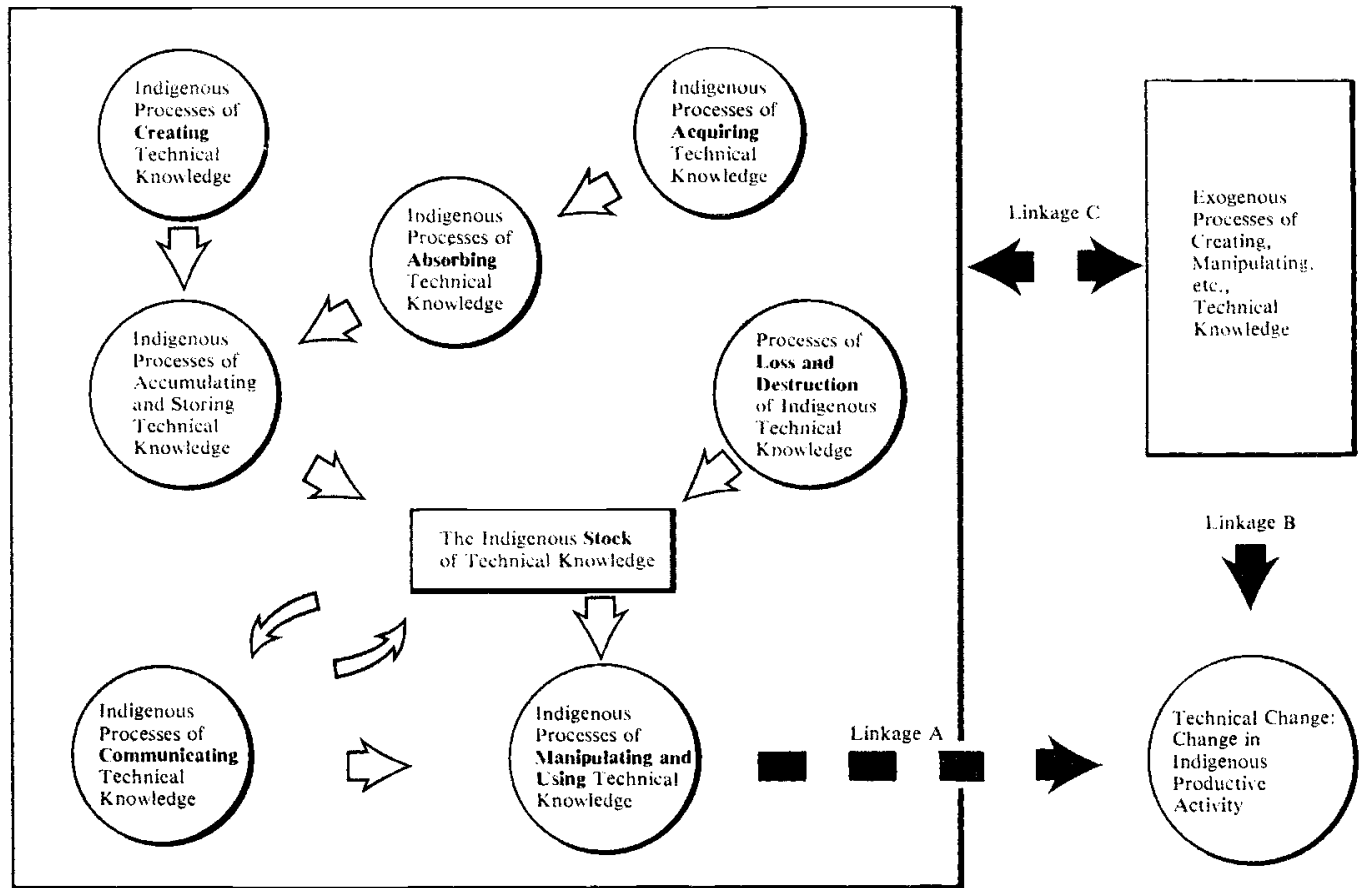

typical. Why? It is not enough simply to point to the existence of ITK as an underutilised resource, and to suggest that, like some decayed mineworking, it may contain the odd valuable nugget. The case is much more basic and farreaching than that, and rests on a diagnosis of the processes which lie behind the patterns of technical change which affect the rural poor.

In outline the diagnosis has four main components:

1. The overwhelming bulk of the technical change which impinges on relatively deprived and rurally-located groups in the third world occurs through linkage $\mathrm{B}$ : it is linked back to processes of creating, manipulating and using technical knowledge which are exogenous to such groups. Both linkages $\mathrm{A}$ and $\mathrm{C}$ are weak or non-existent so that indigenous capabilities play only a marginal role in effecting technical change.

2. As a result of the marginalisation of indigenous technology the patterns of technical change which impinge on the rural poor have a number of undesirable effects. For example, they may make uneconomic use of local resources as inputs to production. The techniques may have input structures with technical (and hence economic) characteristics which lead to their use exclusively or disproportionately by higher income groups, or which lead to a further concentration of control over local resources or locally generated income in the hands of such rural elite groups, or in the hands of urban or foreign groups. The outputs of the new production systems may meet the consumption demands of only relatively privileged groups rather than 'basic needs' of broader sections of the population. ${ }^{3}$ They may fit ill with the local cultural or natural environment, leading to losses in local welfare-even if some individuals or sub-groups do benefit. At the extreme, exogenous techniques may be so inappropriate that they are not used at all and have little

\footnotetext{
3 These distributional effects of technical change may not, of course, be determined solely or at all by the technical characteristics of the new production methods. These may in principle be inherently neutral in terms of the distributional consequences of their use but, within the context of a particular economic and political structure, the lise of the techniques may lead to these types of distributional bias.
} 
consequence apart from wasted costs in developing them. ${ }^{4}$

3. The marginalisation of the existing indigenous technology system seriously constrains the further development of the capabilities within that system. At best their development is limited; at worst they are eroded away. Marginalisation is perpetuated or worsened, and the groups involved do not increase their control over technology and hence over the technical basis of the forms of production with affect their own lives.

To a large extent technological capabilities are learned and augmented by being used. 'Learningby-doing' is a crucial process in the development of technology-related skills-be they the skills of a design engineer, a village blacksmith or a peasant cultivator. To the extent that indigenous technological capabilities are marginal to the process of technical change, the opportunities for 'doing' and hence for 'learning' are limited. At the same time, the propensity to acquire new technical knowledge and skills is likely to depend on expectations of there being some future use for them. Alternatively, if the demands for knowledge already acquired lie outside a society, then those who have already acquired such knowledge are likely to leave the society in order to use it.

If the demand for the use of indigenous technology is very low or intermittent, not only is its development limited, but its very existence may be threatened as those who may have accumulated knowledge lose it, forget it, migrate or die. The technology which once was a vital component of indigenous culture withers awayperhaps to be resurrected only in theses and papers of learned antiquarians and visiting anthropologists. ${ }^{5}$ This decay is likely to weaken even further linkage $A$ between indigenous technical knowledge and technical change. If future technical change involves more complex technical

\footnotetext{
4 For one example of this common phenomenon, sec G. J. Gill, 'Bottlenecks in a Single-Cropping System in Chilalo, Ethiopia: The Acceptance and Relcvance of Improved Farming Equipment', World Development. vol. 5, nos, 9/10. 1977. The case is especially interesting because it involved the development of four irrelevant implenents by enginecrs who, although located in the rural context, were not sufficiently familiar with indigenous production systems.

5 This destructive effect of marginalisation casts into a different perspective the question of destruction of ITK which was raised in the Workshop discussions. The impression given in those discussions was that ITK was destroyed in some form of ahstract cohfrontaton with 'superior' knowledge from elsewhere. This seems likely to he a rare form of the process of destruction as far as rechnical knowledge is concerned. A more common 1 rocess is that which results from the diversion of demands for technical knowledge. or for the products which embody it, towards suppliers outside the society. ITK is probahly not "destroyed'; it just withers away through disuse.
}

knowledge than at present, then one must probably be concerned not merely with arresting the decay of indigenous technical knowledge, but with augmenting it, and therefore with reversing the present patterns of marginalisation of indigenous knowledge and capabilities.

4. The self-perpetuating character of the marginalisation of indigenous technical capabilities gives reason for concern not only because it is likely to perpetuate 'inappropriate' forms of technical change. It is possible to imagine a situation in which wholesale dependence on technical change which was rooted in exogenous technological systems did not result in patterns of technical change which were 'inappropriate' in terms of economic efficiency or the distribution of welfare. But one might still be concerned about the situation simply because the indigenous groups would have no control over, or even involvement in, the processes which changed the technical basis of their lives. Such control and involvement is an objective in its own right, even if it has no functional implications-which it almost certainly has. ${ }^{6}$ A necessary, but not at all sufficient, condition for a group being able to acquire such control or involvement is the availability of a set of technological capabilities within the group. Even a zomby population of 'adopters' and 'non-adopters' of introduced new techniques needs the technical knowledge to decide to adopt or reject if it is to retain any semblance of control over its own destiny. This paper assumes that more control than that is desirable in its own right.

This diagnosis indicates, then, one major structural problem: marginalisation of indigenous knowledge and capabilities because the demands for technical knowledge, which are derived from the demands for new techniques, are met by exogenous knowledge and by exogenous capabilities for creating and using it. The diagnosis also

\footnotetext{
6) Such functional inıplications of involvesnent in effecting technical change have been noted in a study of tubewell development in Bangladesh. Two alternative approaches differed significantly in the extent to which farmers were involved in installation of the wells, and one observer noted: "It is quite probable that installation techniques will have some influtence on farmer utilisation, operation and maintenance, as they did in Comilla. Although there is no way to guantify this psychological aspect, farmers who had participated in the installation of a well, having spent four weeks working on it, are likely to have a much greater understanding of welloperations as well as a feeling of personal investment in it. As a result they may be much more aware of its potential henefit. If on the other hand, the process is one of bringing in heavy equipment which they do not understand and which in one week installs the well and departs, they will not understand how the well works or feel it is anything with which they are associated". See J. W. Thomas, "The Choice of Technology for Irrigation Tubewells in East Pakistan: Analysis of a Development Policy Decision" in C. P Timmer et al., The Choice of Technology in Developing (ountries (some cautionary rales). Harvard, 197.5.
} 
stem from this: the 'inappropriateness' of technical change; the decay of even those stocks of knowledge and capability that exist; and the limited control which can be exerted by 'indigenes' over the technical changes which affect their lives. This structural situation and its consequences seem to justify a major concern with finding ways to use ITK in effecting technical change to a far greater extent than is usual.

\section{What uses might be made of indigenous technical knowledge?}

Discussion of the uses of ITK, for example those in some of the earlier papers, tend to focus on its use in $R$ and $D$. The previous section of this indicates three undesirable consequences which paper argued along broader lines-that it should be used in effecting technical change. Technical change takes place in a large variety of ways, many of which do not involve knowledgecreation by $\mathbf{R}$ and $D .{ }^{\top}$ Also, even when $R$ and $D$ is involved, a wide spectrum of other, complementary, technology-using activities is involved. To illustrate the wide range of possible uses for ITK, in addition to its use in $R$ and $D$, the range of different kinds of technical change process is collapsed here into five categories.

1. Technical change may take place as a result of adaptations or improvements of existing production systems which are carried out autonomously by those operating those systems. Such forms of technical change involving learning to produce more efficiently are common in dynamic 'modern' production sectors. However, even so-called 'traditional' sectors are seldom as technically static as is often suggested-the adaptations and improvements to production methods which are effected by those operating such production systems can be significant. However, as production systems come to embody new types (and perhaps increasingly complex forms) of technical knowledge, the ability of the system operators to adapt and modify these depends on their accumulating relevant technical knowledge in parallel with the acquisition of new production techniques. Without this parallel indigenisation of the technical knowledge which underlies techniques, technical change must depend increasingly on specialised agents of

\footnotetext{
It is widely accepted that the various functions which are labelled as Research and Development are all concerned with creating new knowledge. This need not imply the creation of universally new knowledge. Although elements of knowledge may be known to soineone somewhere. they are oftes re-created in specific situations by researcl and experimentation than acquired from where they are already availahlc.
}

change rather than on the autonomous minor innovative activity of indigenous systemoperators.

2. Technical change may take place as a result of the adoption by producers of new methods developed by others. Very often adoption must be accompanied by adaptation and modification in order to fit the new method efficiently into the existing production system.

Even if technical change is based on methods developed outside a particular social group, an indigenous technological capability is needed to assess and evaluate the new method (to decide on whether and how to use it), to adapt the production activities within which the new method is to be used, and possibly to modify the new method itself. This modification may be carried out by the adopter of the new technique or may have to be carried out, at least partially, by specialists. Even with outside specialists, however, technical knowledge within the group may be needed to identify, specify and communicate the modifications that are necessary.

3. Technical change involving the use of some new method of production may take place through incorporating existing technical knowledge into an item of capital equipment. Such technical change may involve the use of technical knowledge already available to capital goods producers. These specialists in using technical knowledge to embody it in capital goods may be large machinery and equipment producers, small machinery workshops, or village blacksmiths, carpenters and masons. Technical change can be effected in this way without involving anything resembling $R$ and $D$.

If ITK is to be applied in effecting technical change, then its use in this form of change may be important. One would have to be concerned about the acquisition and use of relevant technical knowledge, and maybe about the prior development of the types of non-R and $D$ capability needed to acquire, use, and embody it in capital goods.

4. Technical change may take place as a result of design activities. If a substantially new type of capital good is to be produced, some form of design activity (however rudimentary) is likely to be involved. Design activity may also be involved in effecting types of technical change which involve no new capital goods at all, such as the design of a new cropping pattern, the specification of (new) patterns of fertiliser application, the 
design of a new set of procedures for using water supplies, and so on.

Design is of ten closely linked to $\mathbf{R}$ and $\mathbf{D}$ in order to incorporate newly-created knowledge in a new system of production. However, the specifications of new production systems are often based on existing knowledge. Existing knowledge is selectively drawn upon and synthesised to design a new way of doing things. Such 'existing' knowledge may have been created by $R$ and $D$ at some earlier time, but can be used in designing new methods of production without any further $R$ and $D$ activity. One should also take note of the relative importance of new, $\mathrm{R}$ and $\mathrm{D}$-created knowledge in the specifications for most innovations. Even for very advanced technical systems new knowledge immediately derived from $R$ and $D$ is often only a small part of the total knowledge which designers incorporate into the new system.

So the use of ITK to effect technical change may mean the indigenous use of technical knowledge to carry out this design-based type of technical change. This may imply the prior acquisition of relevant technical knowledge and the prior accumulation of indigenous capabilities to use it.

5. Technical change may take place as a result of $R$ and $\mathbf{D}$. Where existing knowledge is inadequate for specifying efficient and appropriate new methods of production, new knowledge has to be created. Almost anybody can experiment to create new technical knowledge-peasant farmers as well as capital goods producers and design engineers. Knowledge-creation by $R$ and $D$ can then take place entirely inside or entirely outside the indigenous system. Alternatively $R$ and $D$ may take place partly within and partly outside the indigenous system, with different elements of the knowledge needed to develop a new system flowing inside $\rightarrow$ out and outside $\rightarrow$ in.

The variety of forms of interaction between the indigenous and non-indigenous systems is widened further when we take account of all the non-R and $D$ activities which are needed to effect technical change-even $R$ and D-based technical change. The knowledge created by $R$ and $D$ must be incorporated, with large amounts of pre-existing knowledge, into designs and specifications. Parts of these specifications may have to be transformed into capital goods, and the new technique may have to be modified, as may the broader production system within which it is to be used. Technical knowledge must flow between these different activities, and if, as with $R$ and $D$, some of these activities are carried out within the indigenous system and some outside, technical knowledge may flow both inside $\rightarrow$ out and outside $\rightarrow$ in .

In four of these five categories of technical change, then, $R$ and $D$ is not directly involved. In the other, it is not the only activity involved. This is not to state that $R$ and $D$ is unimportant, but rather to indicate that $R$ and $D$ is by no means the only, nor necessarily the main, use for ITK. Other uses may be far more important in order to arrest, and hopefully reverse, the decay of ITK, and to build up greater involvement in and control over technical change on the part of rural people-both as an objective in its own right and as a means to effect more appropriate forms of technical change.

\section{Conclusions}

The preceding discussion of the different tasks for which ITK may be used indicated that technical knowledge may flow from outside into the indigenous technology system where it is transformed and used to effect technical change. In terms of Figure I, the interaction at linkage $\mathrm{C}$ would be largely one way (from outside $\rightarrow$ in): linkage $A$ would be strong, with technical change depending heavily on the indigenous technology system; and linkage $B$ would be weak. This pattern of interaction is, of course, most uncommon. The usual view of technological progress, technical change and rural development sees the creation of new knowledge and its transformation into designs and hardware as tasks for non-rural specialists. Technical change then arises largely and necessarily from the introduction into rural society of techniques created outside it.

If the approach to making use of ITK is taken from within this usual perspective, then it is likely to result in an inside $\rightarrow$ out flow of technical knowledge. ITK will be extracted from its indigenous context for use in exogenous technological activities. This is unlikely to arrest the marginalisation of indigenous technological capabilities. On the contrary it is likely to reinforce the approach to rural development which relies on non-rural institutions, initiatives and specialists. Paradoxically, this way of using ITK could entail yet more non-rural specialists with complex techniques of investigation and analysis in order to know what the indigenes already know! This would add yet another group to the galaxy of non-rural specialists who are allocated by urban society to alleviate rural poverty by developing new techniques for rural society- $R$ and $\mathbf{D}$ 
specialists, consultant and design engineers, extension specialists, village survey specialists, social cost-benefit analysts, and technology assessment wizards.

Dependence on such an ever-expanding panoply of non-indigenous specialised skills and institutions may, nonetheless, be a viable approach to alleviating rural poverty, and they may do a slightly better job if they use bits and pieces of indigenous knowledge.

However, the viability of the approach must surely be questioned when one takes account of the enormity and rate of grow'th of rural poverty, the problems of producing goods and services more efficiently and more equitably, and the variety of socio-economic and natural environments. Which third world societies can in the relatively near future support the massive structure of non-rural specialists and experts required to effect by this approach the widespread, diverse and equitable technical change needed to transform their rural societies?

The answer may well be: 'some'. Some resourcerich countries may also be able to eliminate rural poverty by rapidly absorbing rural populations into high-income, non-rural productive activities. But many economies will neither be able to by-pass the problem this way nor to mobilise the required army of non-rural experts and specialists within an acceptable period of time. For such economies it may be necessary to reverse the whole approach to technical change and rural development.
Such a reversal would mean much more than simply using existing exogenous processes of technical change to devise more appropriate techniques for rural society-even if that effort did incorporate a flow of technical knowledge from inside rural society. The problem with the technical basis of production in rural society is not so much its inappropriate techniques as the appropriateness or otherwise of the processes by which it is changed. A strategy for improvement must be critically concerned with devising more appropriate processes of effecting technical change. This effort might usefully focus on how exogenous knowledge can be indigenised, and on augmenting and reinforcing indigenous capabilities for creating, acquiring, absorbing, communicating and using technical knowledge. To effect this kind of reversal, concern about the technological relations between rural society and the rest of the world would have to shift its focus from the flow of techniques to the flow of technical knowledge. Within that, the flow running outside $\rightarrow$ in would be far more important than that flowing inside $\rightarrow$ out.

For some problems of rural poverty one might not be able to shift far in this direction, but how far one can usefully go in any situation must remain at present an open question. However, any change in technology-centred interaction within the context of present technological and other forms of inequality is unlikely on its own to be sufficient; but it may be a necessary part, together with other measures, of any strategy to enable the rural poor themselves to alleviate their poverty. 